- Quarterly Technical Report -

$$
\begin{aligned}
& \text { DUE/PC/9.5E-T/PROBPEDO } \\
& \text { finin } 241983 \\
& 08 T 1
\end{aligned}
$$

DEVELOPMENT AND USE OF AN APPARATUS TO MEASURE

THE DYNAMIC SURFACE PROPERTIES OF COAL-WATER-SLURRY FUELS

FOR APPLICATIONS TO ATOMIZATION CHARACTERISTICS

\author{
Contract No. DE-FG22-92PC'\$2156
}

(Reporting period: From 11/01/92 - 01/31/93)

$\mathrm{DOE} / \mathrm{PC} / 92156--\mathrm{T} 1$

DE93 009656

submitted for

Dr. S. S. Kim, Project Manager

U. S. Department of Energy-Pittsburgh Energy Technology Center

Pittsburgh, PA 15236

prepared by

K. D. Kihm

Department of Mechanical Engineering

Texas A\&M University

College Station, Texas 77843-3123

(409) 845-2143

Fax (409) 862-2418

January 31, 1993

U.S. DOE Patent Clearance is not required prior to the publication of this document. 


\section{Development and Use of an Apparatus to Measure the Dynamic Surface Properties of Coal-Water Slurry Fuel: for Applications to Atomization Characteristics}

K. D. Kihm, Principal Investigator

Department of Mechanical Engineering

Texas A\&M University

College Station, Texas 77843-3123

(409) 845-2143

(Reporting period: From 11/01/92 - 01/31/93)

\section{INTRODUCTION}

The Texas A\&M University (TAMU) has been awarded a DOE contract to study dynamic properties and atomization characteristics of coal-water slurry (CWS) fuels. Additives are essential for better mixing and stable suspension of coal powders and these additives change CWS properties. Dynamic properties will have major effects on CWS fuel atomization, which constitutes highly dynamic processes, and will determine the combustion as well as the pollutant formation behaviors. The dynamic surface tension of CWS fuels can be much higher than the corresponding static surface tension. Experimental study of correlating the atomization characteristics and dynamic properties of CWS fuels will be performed during the contract period.

The research projects consists of five tasks. Task 1 selects appropriate additives and surfactants for CWS fuels by measuring the stabilizing characteristics and critical micelle concentrations (CMC). Task 2 implements the dynamic surface tensiometer operating based on the formation of maximum bubble pressure. Task 3 measures dynamic properties of CWS fuels as functions of bubble frequency while the fuel parameters are varied. The fuel parameters include coal loading, type of stabilizer and type of surfactant. Task 4 will devise a CWS fuel spray system and Task 5 will measure the spray droplet sizes using a laser diffraction technique.

Task 1 and Task 2 have been complete $\mathrm{J}$ and Task 3 is being carried out at present. TAMU plans to complete Task 3 by March and commence Task 4 in April. In the present report the achievement in Tasks 1 and 2 is presented and preliminary result of Task 3 is also described.

\section{ACCOMPLISHMENT}

Items of Task 1 included preparation of CWS fuel samples and determination of additives and surfactants for mixing of coal powder and water. In order to define optimal amount of each 
surfactant for upcoming dynamic property measurement, a critical micelle concentration (CMC) was determined from the measurements of static surface tension.

Task 2 implemented the bubble pressure tensiometer and carried out preliminary test of the instrument. The preliminary test was made using distilled water and the result ensured a satisfactory accuracy of the instrument.

\section{Properties of Coal Powder}

Pulverized coal for the present study was provided by Mr. David Wildman of DOE-PETC. Data from the proximate and the ultimate analy s of the coal were also provided and are summarized in Table 1. The tested coal was originally mined from Upper Elkhorn seam in Virginia and pulverized by the DOE-PETC grinding facility. Size distribution of the coal particulates which were measured with a Coulter counter at DOE-PETC is presented in Fig. 1. The high ash contents of $2.56 \%$ and relatively large volume mean diameter (VMD) of $55 \mu \mathrm{m}$ indicated that the coal powder was prepared for industrial applications such as boilers. For applications for internal combustion engines, the coal must be micronized to be less than $5 \mu \mathrm{m} \mathrm{VMD}$ and the ash contents must be maintained less than $1 \%$ (Kihm et al.).

Table 1. Results of coal analyses* (Upper Elkhorn seam, Virginia)

\section{Proximate Analysis (dry basis)}

$\begin{array}{ll}\text { Moisture } & 0 \% \\ \text { Volatile Matter } & 36.75 \% \\ \text { Fixed Carbon } & 60.69 \% \\ \text { Ash } & 2.56 \% \\ \text { Sulfur } & 0.77 \% \\ \text { Btu/lb } & 14950\end{array}$

\section{Ultimate Analysis}

Carbon

Hydrogen

Nitrogen
$83.66 \%$

$6.38 \%$

$1.56 \%$

*The data were provided from Wildman (1992) 
Figure 2 shows a scanning electron microscope (SEM) picture of the coal particulates. The length of the reference bar at the bottom of the picture is $50 \mu \mathrm{m}$ and most coal particulates are smaller than or approximately equal to $50 \mu \mathrm{m}$. The particle size spectrum shown in Fig. 1 might have been slightly overestimated because of the clustering of particles during the measurement.

\section{Selected Additives}

TAMU has collaborated with WITCO Corporation in Houston, a leading surfactant manufacturing company, in selecting and identifying appropriate additives for effective coal-water mixing. Two different kinds of additive had to be considered, an additive for the suspension stability and a surfactant for lowering the mixture surface tension. Without stabilizing additive the coal particulates were separated from the mixture very rapidly and resulted in a thick layer of coal powder at the bottom of the container within minutes. We concluded that a stabilizer had to be considered as an essential ingredient for CWS fuel preparation. Flocon, an additive widely used by food industry, was selected for the stabilizer. After some trial-and-error procedures, a proper dosage of Flocon was determined to be $0.3 \%$ in weight concentration. Coal powder was mixed with deionized and distilled water using a magnetic stirrer.

The selected surfactants and their critical micelle concentration (CMC) data are presented in Table 2. The CMC of each surfactant exists which minimizes the static surface tension. Surfactant concentrations greater than CMC do not further decrease surface tension.

Table 2. Selected surfactants for CWS mixture and their critical micelle concentration (CMC)

Surfactants

Witconol NP-100

Ammon DDBS (Type A)

Ammon DDBS (Type B)

Witconate $1223 \mathrm{H}$

Witconate P-1059
CMC

$-\%$ in weight ratio -

0.0041

0.11

0.083

0.12

0.05

These CMCs were measured for water-based solution using a Du-Nouy ring tensiometer. Figure 3 shows the measured static surface tension as a function of weight ratio for the case of Witconol NP-100 showing $0.0041 \%$ CMC. Although not shown, results of measured static surface tension versus surfactant concentration for the other four surfactants were documented at TAMU. When 
coal powder is added, a significant increase of CMC is expected primarily because of the absorption of surfactant occurring on the porous surface of coal particulates.

\section{Critical Micelle Concentration of CWS Mixture}

Measurement of static surface tension of CWS mixture was carried out for different coal weight loadings ranging from 40 to $60 \%$. Figure 4 shows the static surface tension versus Witconol NP100 concentration for 40,50 and $60 \%$ coal loading cases. For all three coal load cases about $0.1 \%$ CMC was measured for Witconol NP-100. More than an order of magnitude increase in CMC for CWS mixture compared with that of the water-based solution has been shown and this is believed to attribute to the absorption of the surfactant by coal particulates. Measurements of dynamic surface tension were made at or higher surfactant concentration than the CMC so that minimum static surface tension could be ensured. The determination of CMC for CWS samples will be repeated for each surfactant listed in Table 2. The current report, however, presents dynamic surface tension results of CWS mixture only with Wiiconol NP-100. Effects of other surfactants will be presented in the successive quarterly report in April.

\section{Maximum Bubble Tensiometer}

Dynamic surface tension was measured with a KRUSS Model BP1 tensiometer operating based on the maximum bubble pressure detection technique (Brian and Chen, 1987). Figure 5 shows an illustration of the operating principle of the maximum bubble pressure tensiometer. The CWS was contained in a vessel which comprised a specially designed capillary tube with a small outlet diameter of an order of one millimeter. As bubbles were formed and separated from the capillary tube, pressure fluctuations were recorded. For each cycle of bubble formation, maximum air pressure for minimum bubble radius was recorded as the bubble was detached from the capillary outlet. The dynamic surface tension was calculated as a function of the bubble frequency from the measured maximum bubble pressure substituted into a simple relation

$$
\sigma=\left(p_{\max }-\rho g h\right) r_{d} 2
$$

where $\rho$ is the liquid (CWS) density, $g$ is the gravitational acceleration, $h$ is the height above the capillary outlet, and $r_{c}$ is the radius of the capillary outlet. The maximum bubble pressure, $p_{\max }$, is corresponding to the inside air pressure when the radius of the growing bubble is equal to the capillary radius, $r_{c}$. The accuracy of the tensiometer operation was tested by measuring surface tension for distilled water. The result ensured a satisfactory measurement accuracy showing less than $2 \%$ deviations from the surface tension values listed in CRC Handbook by Weast (1988). 


\section{Dynamic Surface Tension Measurement}

Figure 6 presents results of dynamic surface tension of water-based Witconol NP-100 solution as functions of the bubble frequency for different surfactant concentrations higher than the CMC of $0.0041 \%$. When the bubble frequency was low, all the curves exhibited a similar trend to approach the static surface tension of $31 \mathrm{mN} / \mathrm{m}$ (Fig. 3). Dynamic surface tension increased with increasing bubble frequency and approached the surface tension of pure water, $73 \mathrm{mN} / \mathrm{m}$. As the bubble frequency increased the surfactant did not have enough time to migrate to the bubble surface and could not effectively lower the surface tension there. This was more distinctively observed for the cases of 0.005 and $0.01 \%$ that were relatively close to the static CMC. For the surfactant concentrations of 0.1 and $0.2 \%$ far exceeding the CMC, because of relatively more amount of surfactant available the dynamic surface tension showed significantly lower values than $73 \mathrm{mN} / \mathrm{m}$ even at the highest bubble frequency. This implied that the $\mathrm{CMC}$ for dynamic processes such as an atomization had to be redefined and the dynamic CMC should be noticeably higher than the static CMC.

Figure 7 presents dynamic surface tension measured for $40 \%$ coal-loaded CWS mixture with different concentrations of Witconol NP-100 surfactant. Continuous decrease of dynamic surface tension was seen again for the surfactant concentrations exceeding the static CMC of $0.1 \%$. In comparison with Fig. 6, one thing to note is that the dynamic surface tension of CWS mixture was noticeably higher than its counterpart of the water-based solution without coal under the same surfactant concentration $(0.1 \%)$. The probable reason for this is the absorption of surfactant occurring on the porous surfaces of coal particulates. This preliminary result also suggested that the dynamic surface tension of CWS mixture would decrease with increasing surfactant concentration far beyond the static CMC level and the atomization characteristics of CWS fuels could be dramatically improved by properly dosing a surfactant higher than its CMC.

\section{FUTURE RESEARCH PLAN}

For future investigation, an extensive set of static and dynamic surface tension measurements will be carried out for wide ranges of surfactant concentrations as well as for different coal loadings. The set of measurements will be repeated for all five surfactants listed in Table 2 so that individual rankings can be evaluated in terms of surface tension levels. These data and rankings will construct a basis for the upcoming study of the effects of additives on CWS fuel atomization. 


\title{
ACKNOWLEDGMENT
}

The Principal Investigator would like to gratefully acknowledge Mr. David Wildman of DOEPETC for his providing the coal powder and its property data, and Dr. Paul Berger at WITCO in Houston for his valuable advice in selecting appropriate additives and also for letting us to use their instrument in measuring static surface tension of CWS fuel samples.

\section{REFERENCES}

[1] Brian, B. W., and Chen, J. C., (1987), "Surface Tension of Solid-Liquid Slurries," AIChE, Vol. 33, No. 2, pp. 316-318.

[2] Kihm, K. D., Terracina, D. P., Payne, S. E., and Caton, J. A., "Synchronized Droplet Size Measurements for Coal-Water Slurry Sprays of an Electronically-Controlled Accumulated Fuel Injection System," ASME Journal of Engineering for Gas Turbines and Power (submitted for publication).

[3] Weast, R. C. (ed.), (1988), CRC Handbook of Chemistry and Physics, CRC Press, Boca Raton, F-34.

[4] Wildman, D., DOE-PETC, (1992), personal communication: "Measured Coal Properties".

\section{DISCLAIMER}

\begin{abstract}
This report was prepared as an account of work sponsored by an agency of the United States Government. Neither the United States Government nor any agency thereof, nor any of their employees, makes any warranty, express or implied, or assumes any legal liability or responsibility for the accuracy, completeness, or usefulness of any information, apparatus, product, or process disclosed, or represents that its use would not infringe privately owned rights. Reference herein to any specific commercial product, process, or service by trade name, trademark, manufacturer, or otherwise does not necessarily constitute or imply its endorsement, recommendation, or favoring by the United States Government or any agency thereof. The views and opinions of authors expressed herein do not necessarily state or reflect those of the United States Government or any agency thereof.
\end{abstract}




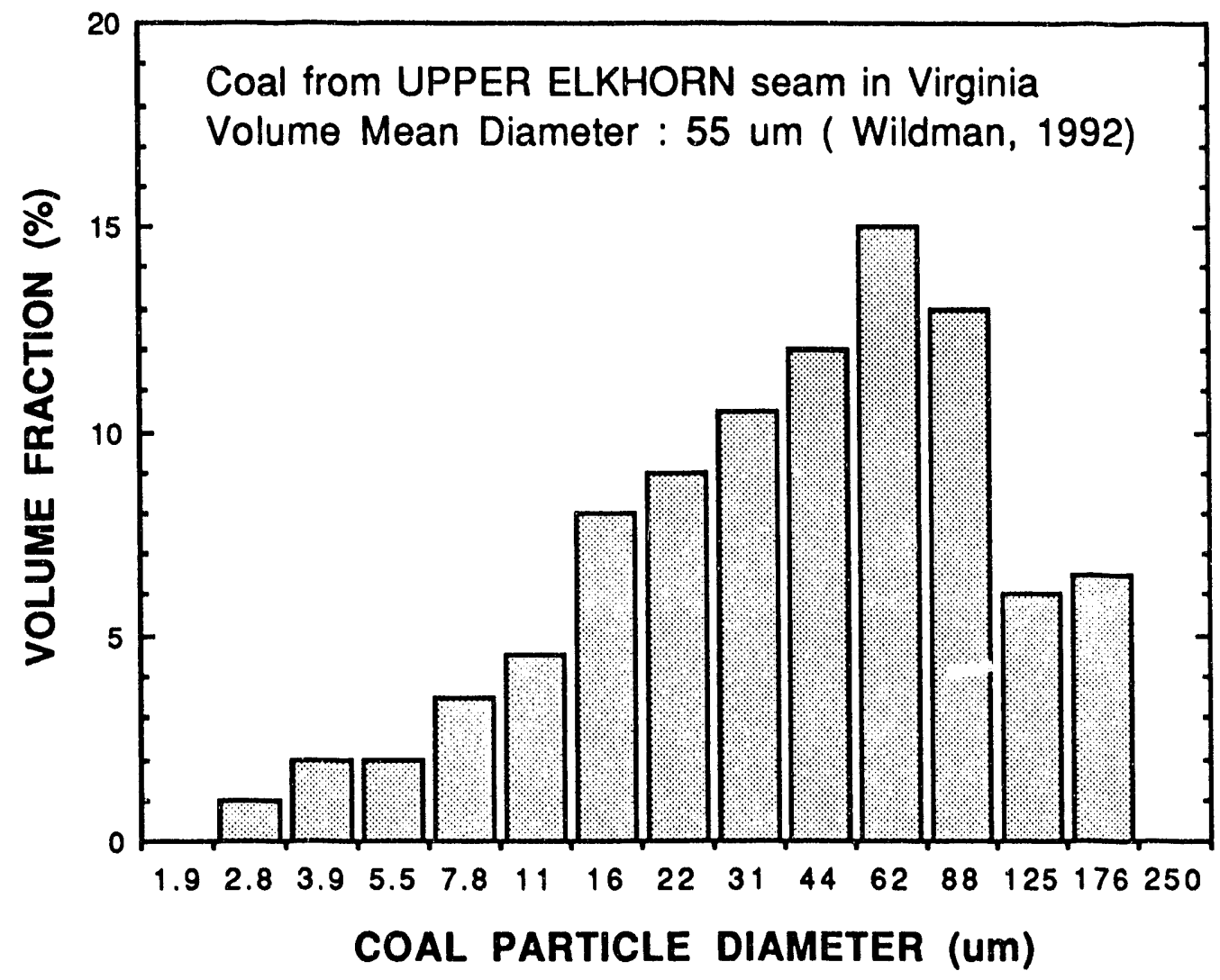

Fig. 1 Measured size distribution of coal particulates 


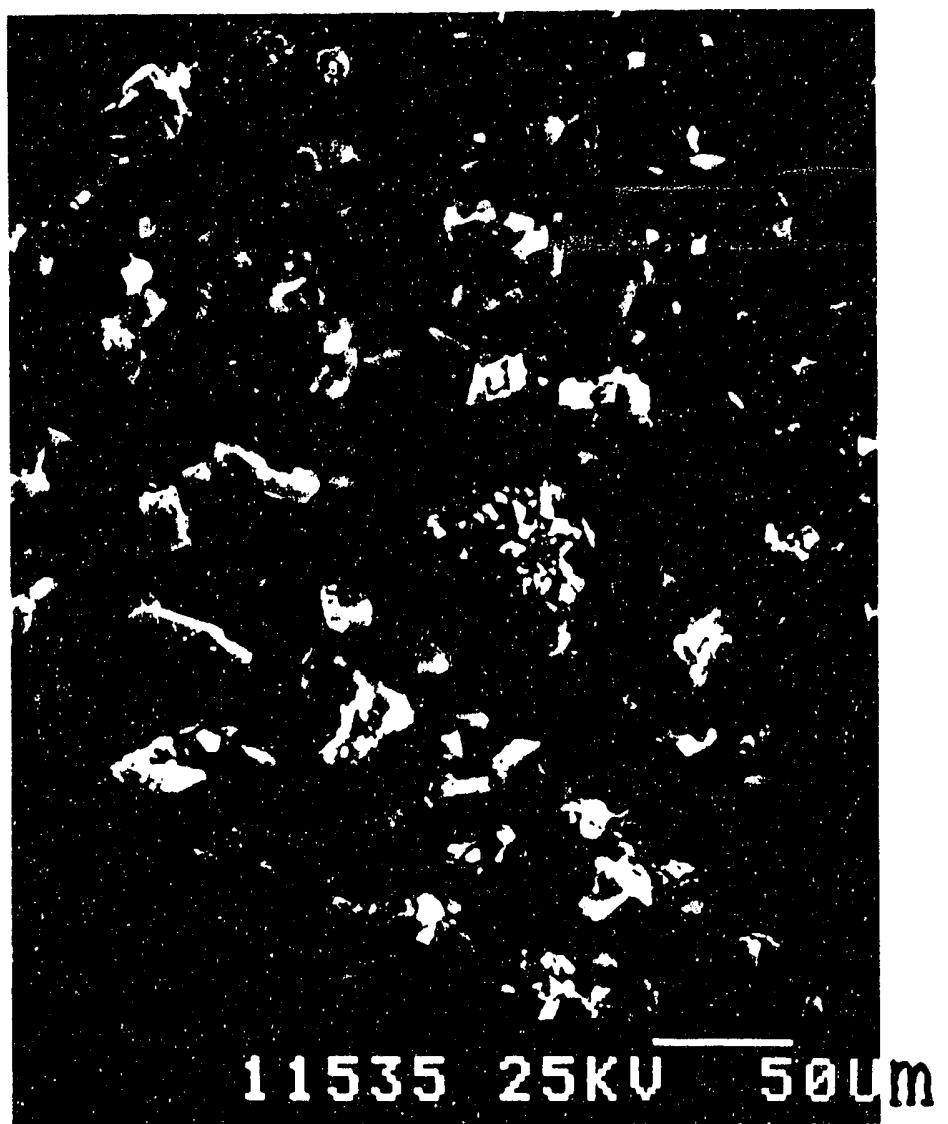

Fig. 2 SEM (Scanning Electron Microscope) picture of coal particulates 


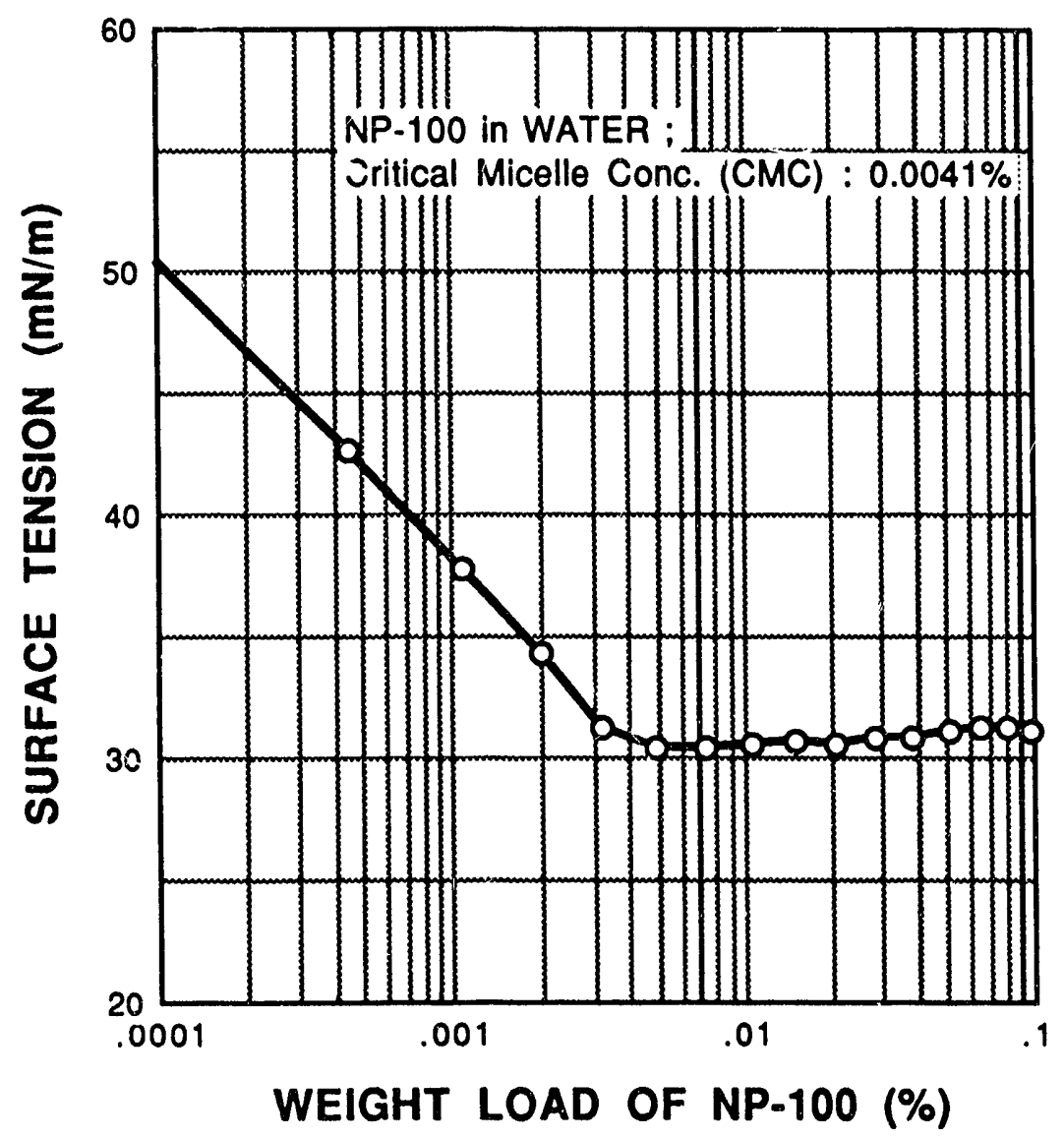

Fig. 3 Static surface tension of mixture of Witconol NP-100 and distilled water 


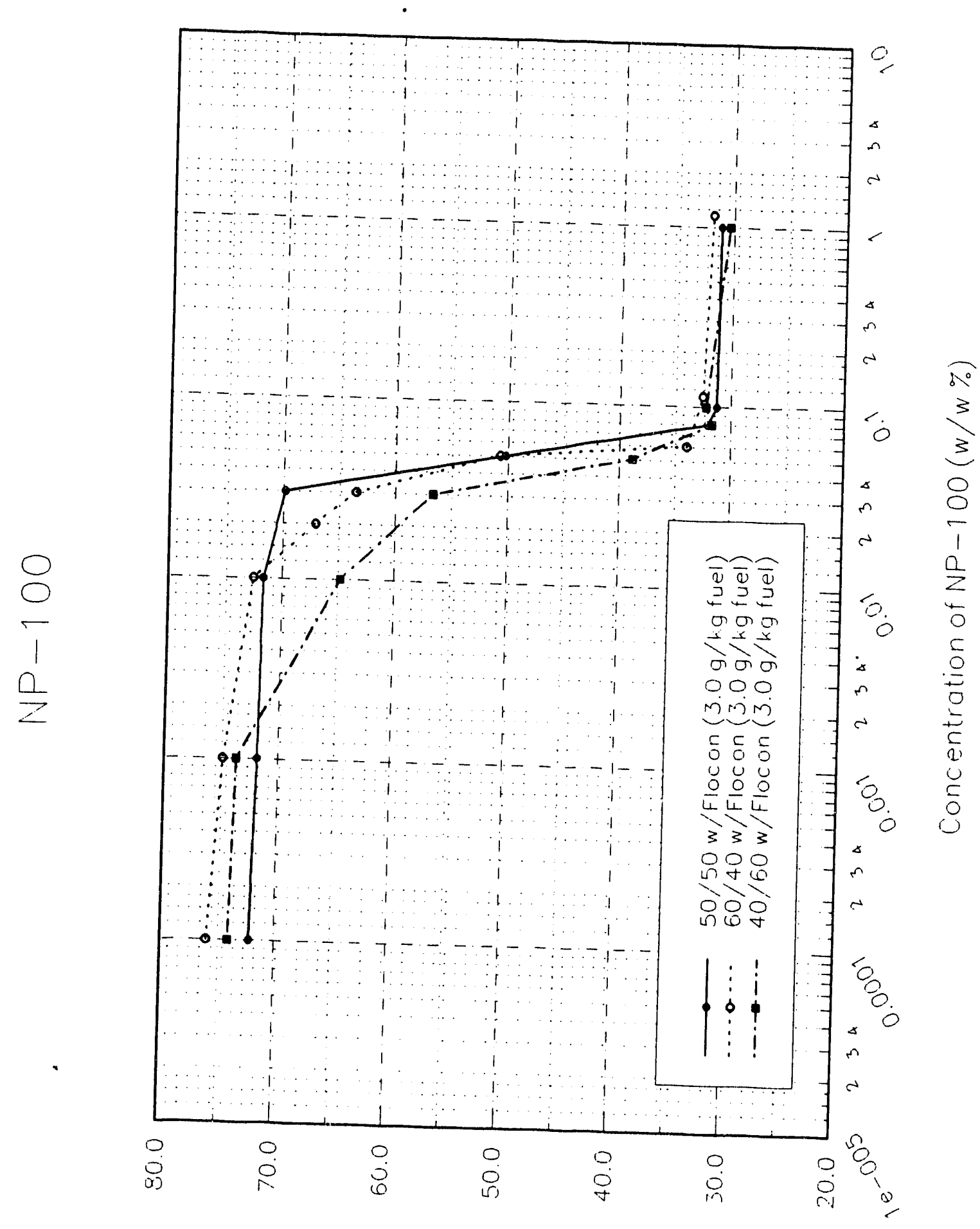

品

(u! / vu) uo!sua d a sofuns 

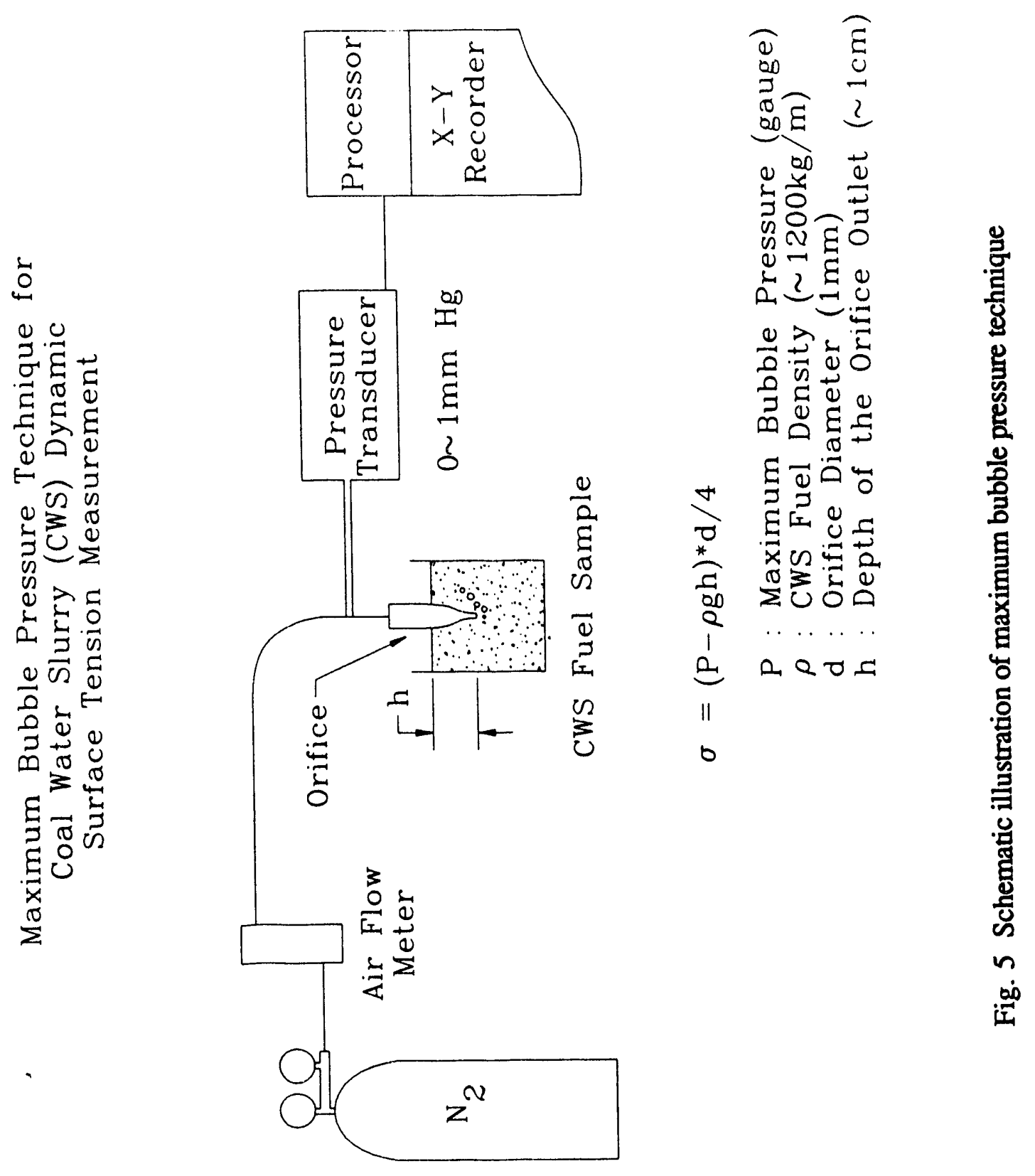




Fig. 6 Dynamic surface tension of distilled/deionized water solution with different concentrations of Witconol NP-100 $\left(\mathrm{CMC}=0.0041 \%, \mathrm{SG}=0.9986, \mathrm{~T}=19.7^{\circ} \mathrm{C}\right)$ 


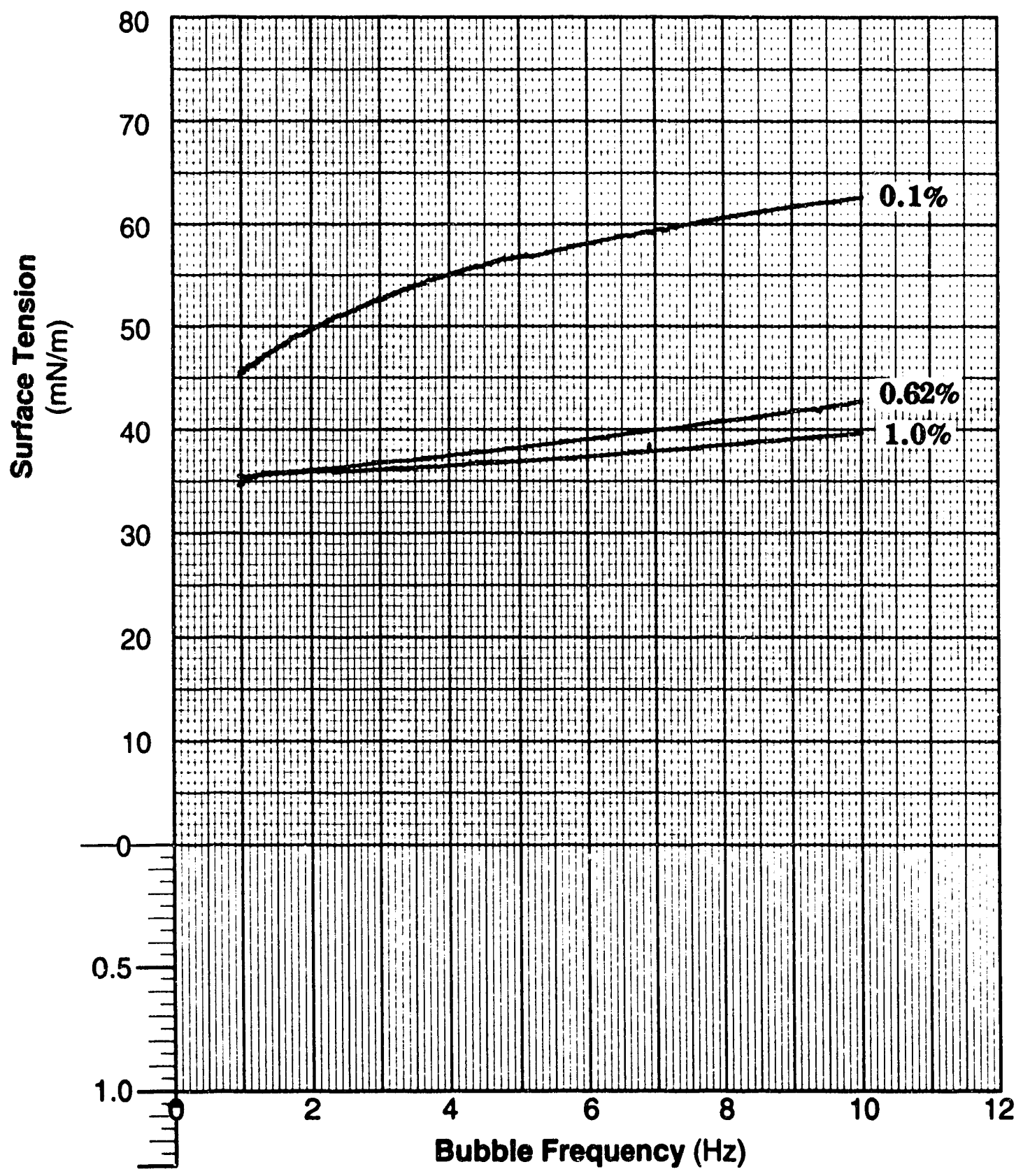

Fig. 7 Dynamic surface tension of CWS mixture with $40 \%$ coal in weight for different concentrations of Witconol NP-100 $\left(\mathrm{CMC}=0.1 \%, \mathrm{SG}=1.064, \mathrm{~T}=20^{\circ} \mathrm{C}\right)$ 

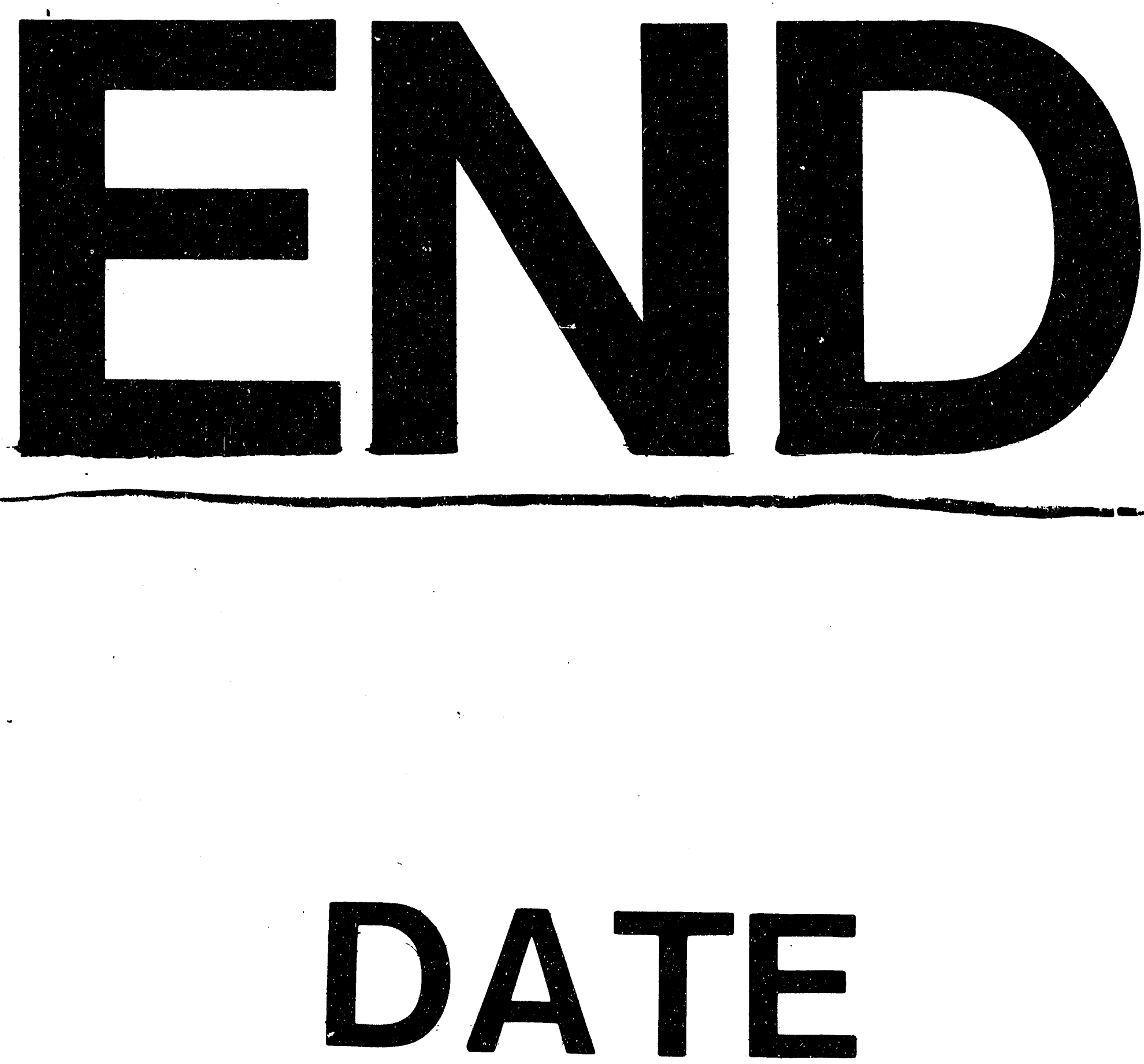

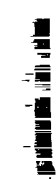
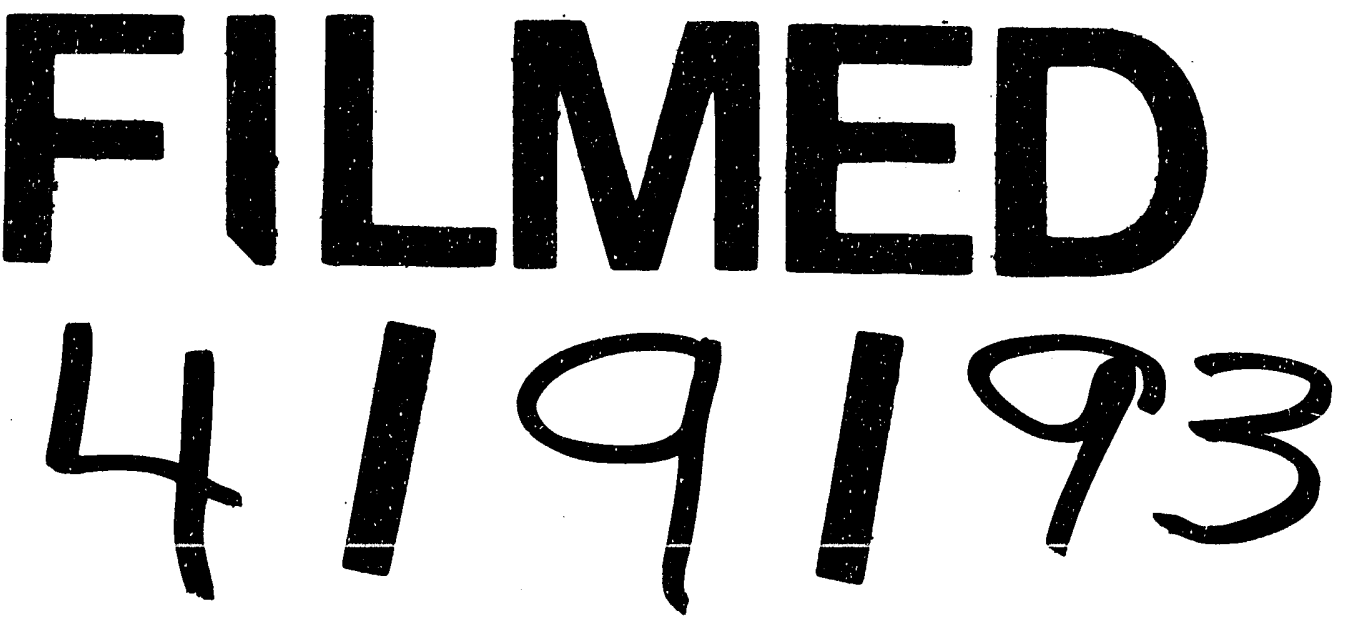
